\title{
SURGICAL SITE INFECTION IN LAPAROTOMY
}

Dr. Pashupati N. Bhatta, ${ }^{1}$ Dr Umesh Kumar Yadav ${ }^{1}$, Dr. Gorakh N. Mishra, ${ }^{1}$ Dr. Randhir Jha, ${ }^{1}$ Dr. Kumar Shrestha ${ }^{2}$

\section{ABSTRACT}

\section{INTRODUCTION:}

Surgical site infection (ssi) is one of the most common surgical complications which increases the rate of morbidity and mortality and increases the health care cost by prolonging the hospital stay.

\section{AIMS AND OBJECTIVES:}

The main objective of the study was to find out the incidence of ssi in emergency laparotomy in general surgery and to find out the associated risk factor for ssi.

\section{MATERIAL \& METHODS:}

Study was carried out in national medical college, Birgunj from January 2011 to June 2012 after getting ethical clearance from Institutional Review Committee National Medical College. Total 200 cases were included in study and follow up done up to 30 days postoperatively.

\section{RESULTS:}

Out of 200 patients, 76 patients developed ssi. The total incidence of ssi was $38 \%$. The rate ssi in clean-contaminated, contaminated and dirty wound were $18.2 \%, 33.3 \% \& 45.5 \%$ respectively. Age, type of surgical operation and prolonged duration of surgery were the significant risk factor for ssi while sex, BMI were not statistically significant. The median length of hospital stay with ssi was 16 days while the median length of hospital stay without ssi was 10 days.

\section{CONCLUSION:}

The rate of ssi was found to be higher in our study in comparison to western study but neariy same when comparing to study of Asian countries. so, we emphasize for the need of evidence based infection control and recommend for better surveillance program me for control of ssi in each hospital.

KEYWORDS: Emergency surgery. SSI.

1. Department of General Surgery, National Medical College, Birgunj.

2. Department of Surgery, NAMS, Bir Hospital, KTM.

Correspondence:

Dr. Pashupati Bhatta,

National Medical College, Birgunj, Nepal.

E-mail:pashupati_bhatt@yahoo.com,

Phone: +977-9841281810 


\section{INTRODUCTION:}

Exploratory laparotomy is one of the most common surgical procedure. This procedure is mostly done in emergency condition like, DU perforation, gastric, ileal perforation, traumatic conditions etc. whereas in abdominal malignancies and other abdominal condition OT is been planned on elective basis but some cases needs emergency laparotomy. In spite of all aseptic antiseptic condition technique and prophylactic antibiotics ssi is still a major problem(1). Ssi can be categorized into superficial incisional, deep incisional and organ or space related.It increases the morbidity mortality and hospital stay of patient. In surgical practice, most of the antibiotics are used as surgical prophylaxis to reduce the post operative wound infection. Reduction in ssi can improve the quality service of hospital and it can decrease the mortality and morbidity rate as well as cost effective to patient(2). This study was plannedto detect the actual incidence of ssi on lapatoomy cases on general surgery dept. and to identify the risk factor associated to increase the ssi rate.

\section{MATERIALSAND METHODS:}

This prospective study conducted in national medical college and teaching hospital in the department of general surgery over a period of $18 \mathrm{mths}$ (jan2011-june2012). Total 200 cases considered for study. ethical clearance was obtained from ethical committee of our institution before the study started, all abdominal surgery including age $>14$,traumatic, non traumatic were considered for this study. Those patient who were taking pre op antibiotics more than 7 days, those who were transferred to another hospital after surgery and those who died before development of ssi were excluded form study. Ssi was diagnosed based on the criteria of centers for disease control and prevention (cdcp) definition of ssi (3). Wound class was considered as clean, clean- contaminated, contaminated, dirty according to national research council classification criteria (4).Variables included were age, sex, duration of surgery, type of wound, bmi, length of hospital stay. The national nosocomial infections surveillance (nnis) risk index was calculated (4). Including procedure time, contaminated and dirty wound and ASA scoring

\section{STATISTICALANALYSIS:}

Analysis processed in the statistical package for social science (SPSS) Software for window. The Association of variables was tested using the test of statistical significance, chi-square test was used and a P- value $;<0.005$ was considered as significant. Findings were showed in tables.
Sex distribution and SSI (\%)

\begin{tabular}{|l|r|r|r|r|}
\hline \multirow{2}{*}{ Sex } & \multicolumn{2}{|c|}{ SSI Present } & \multicolumn{2}{c|}{ SSI Absent } \\
\cline { 2 - 5 } & Number & $\%$ & Number & $\%$ \\
\hline Male & 56 & 38.9 & 88 & 61.1 \\
\hline Female & 20 & 35.7 & 36 & 64.3 \\
\hline
\end{tabular}

P-value: $0.402(>.05)$

Duration of operation and SSI (\%)

\begin{tabular}{|r|r|r|r|r|}
\hline \multirow{2}{*}{$\begin{array}{l}\text { Duration of } \\
\text { operation }\end{array}$} & \multicolumn{4}{|c|}{ Surgical Site Infection } \\
\cline { 2 - 5 } & \multicolumn{2}{|c|}{ SSI Present } & \multicolumn{2}{c|}{ SSI Absent } \\
\cline { 2 - 5 } & Number & $\%$ & Number & $\%$ \\
\hline$<2$ hours & 17 & 18.3 & 76 & 81.7 \\
\hline $2-3$ hours & 47 & 51.6 & 44 & 48.4 \\
\hline$>3$ hours & 12 & 75.0 & 4 & 25.0 \\
\hline
\end{tabular}

P-value: $0.000(<.05)$

\section{Wound class and SSI (\%)}

\begin{tabular}{|l|r|r|r|r|}
\hline \multirow{2}{*}{ Wound Class } & \multicolumn{4}{|c|}{ Surgical Site Infection } \\
\cline { 2 - 5 } & \multicolumn{2}{|c|}{ SSI Present } & \multicolumn{2}{c|}{ SSI Absent } \\
\cline { 2 - 5 } & Number & $\%$ & Number & $\%$ \\
\hline Clean- contaminated & 8 & 18.8 & 36 & 81.8 \\
\hline Contaminated & 8 & 33.3 & 16 & 66.7 \\
\hline Dirty & 60 & 45.5 & 72 & 54.5 \\
\hline
\end{tabular}

P-value: $0.005(<.05)$

Length of hospital stay with SSI in days

\begin{tabular}{|l|r|r|}
\hline \multirow{2}{*}{} & \multicolumn{2}{|c|}{ Length of hospital stay } \\
\cline { 2 - 3 } & With SSI & Without SSI \\
\hline Mean & 18.74 & 10.65 \\
\hline Median & 16.00 & 10.00 \\
\hline Minimum & 4 & 7 \\
\hline Maximum & 35 & 21 \\
\hline
\end{tabular}




\section{RESULTS:}

In the present study total 200 patient included who underwent emergency exploratory laparotomy for different acute abdominal conditions. Out of 200 patient $144(72 \%)$ were male and $56(28 \%)$ were female. The incidence of ssi in male were $38.95 \%$ and in female were $35.7 \%$ which was statistically not significant. P value; $0.042(>0.05)$ (Table 1) Depends upon duration of operative time $<2 \mathrm{hrs}, 2-3 \mathrm{hrs},>3$ hrs the no. of patients were 93,91, and 16 respt.and the percentage of ssi in these groups was $1.3 \%, 51.6 \%$, and $75 \%$ which shows increase in ssi with increase in ot time. P -.000 $(\mathrm{P}<.05)($ Table 2)

The percentage of ssi in clean contaminated, contaminated and dirty wound was $18.8 \%, 33.3 \%, 45.5 \%$ which was significant. P-.005 (<.05) The no. of patient with BMI $<20,20$ $25,25-30$ were $64,112,24$ respt. In these groups the percentage of ssi was 43.8,32,1, and 50which was not significant. P- .136 $(>.05)$ similarly the mean length of hospital stay of patient with ssi 18.74 days with standard deviation $\mathrm{n}$; of 8.294 while mean length of hospital stay of patients without ssi was 10.65 days with standard deviation of 3.571. (Table 4)

\section{DISCUSSION:}

The overall infection rate in abdominal surgery varies from surgeon to surgeon, hospital to hospital, one procedure to another and even differ from one patient to another (5). In our study the rate of ssi was $38 \%$. This is much higher compared to other study because cases were exploratory laparotomy and emergency. Much study done on Asian countries shown ssi rate ranging from $6.09 \%-38.7 \%(1,6,7,8)$. The infection rate is much higher in Asian countries than in others. In USA it is $2.8 \%$ and is $2.5 \%$ in European countries (1). Increased rate of ssi in Asian countries probably due to poor set up of hospital and lack of attention toward the infection control measures. A statistically significant association was observed between the rate of ssi, duration of operation, wound class, BMI and length of hospital stay.

In our study prolonged duration of operation was associated with increased risk of ssi which was statistically significant. Previous studies have assessed the influenced of prolonged operation as a risk factor for ssi (9) procedures that take longer than $2 \mathrm{hrs}$. are associated with surgical site infection $(10,11)$. Similarly wound class was associated with increased risk of ssi which was statistically significant. The reported rate in our study was (12) lower than the other study which revealed that ssi rate in clean contaminated and contaminated was $35.5 \%$ and $77.7 \%$ respt. Where as in our study it was comparable to the study(13) which revealed that ssi rate in clean contaminated, contaminated and dirty was $12.4 \%, 36.5 \%$, and $40 \%$ respectively. BMI was not statistically significant with ssi in our study. A study report (14) revealed that BMI of 25 or more was significant risk factor for ssi.

The mean length ; of hospital stay with ssi was 18.74 days whereas mean length of hospital stay without ssi was 10.65 days. the study showed nearly 2 fold difference between ssi and without ssi group which consistent with study done in the other countries $(10,15,16)$.

\section{CONCLUSION:}

Surgical site infection is increasingly recognized as a measure of the quality of patient care by surgeons, infection control practioners. Although ssi cannot be completely eliminated but can be reduced. Age, duration of operation, wound class are significant risk factor for increasing ssi. Increasing length of hospital stay with ssi increases the economical burden to patient and economical burden to country.

\section{REFERENCES:}

1. Mahesh $C$ B, Shivakumar S, Suresh BS, Chidanand SP, Vishwanath Y.A prospective study of surgical site infection in a teaching hospital. Journal of clinical and diagnostic research 2010 October; 4:3114-9.

2. Nandi PL, Rajan SS, Mak KC, Chan SC, So YP. Surgical wound infection. HKMJ 1999; 5:82-6.

3. Horan TC, Gaynes RP, Marton WJ, et al: CDC definitions of nosocomial surgical site infections, 1992: A modification of $C D C$ 'S definitions of surgical wound infections. Infect control Hosp. epidemiol 13:606-608, 1992.

4. Ercole FF, Starling CEF, Chianca TCM, Carneiro M. applicability of the national nosocomial infections surveillance system risk index for the prediction of surgical site infections: A Review. The Brazilian journal of infectious diseases 2007; 11(1):134-41.

5. Yohannes $Y$, Mengesha Y, Tewelde Y. Timing, choice and duration of peri-operative prophylactic antibiotic use in surgery; A teaching hospital based experience from Eritrea, in 2009. Journal of Eritrean medical association 2009; 65-7.

6. Lilani SP, Jangale N, Chowdhary A, Daver GB. Surgical site infection in clean and clean contaminated cases. Indian $J$ Med Microbiol 2005; 23:249-52.

7. Anvikar AR, Deshmukh AB, Karyakarte RP, Damle AS, Patwardhan NS, Malik AK, et al. a one year prospective study of 3,280 surgical wounds. Indian J Med Microbiol 1999; 17: 129-32. 
8. Ganguly PS. Khan Y. Malik A. Nosocomial infection and hospital procedures. Indian J. common Med.2000; 990-1014.

9. G. Leong, J. Wilson and A. Charlett, duration of operation as risk factor for surgical site infection: comparison of English and US data, J Hosp. Infect 63.

10. Haley R.W, Culver D. H, Morgan White J.W, Emori T.G, and Hooton T.M: identifying patients at high risk of surgical wound infection: a simple multivariate index of patient's susceptibility and wound contaminations. AMJ Epidemiol 1985; 121(2):206-15.

11. Jepsen O.B, Larsen S.O, and Thomsan V.F: postoperative wound sepsis in general surgery ii. An assessment of factors influencing the frequency of wound sepsis. Acta Chir Scand suppl 1969; 396: 80-90.

12. Umesh S.Kamat, AMA Fereirra, M.S. Kulkarni, D.D Motghare: A prospective study of surgical site infection in teaching hospital in Goa. Indian J. Surgery (may-June 2008) 70:120-124.
13. Sangrasi A.K, Leghari A.A, Memon A, Talpur A.K, Qureshi G.A. Memon J.M: surgical site infection rate and associated risk factors in elective general surgery at public sector medical university in Pakistan. Int. wound J. 2008 Mar; 5(1): 74-8.

14. Imai E, Ueda M, Kanao K, Kubota T, Hasegawa H, Omae K, Kitajima M: surgical site infection risk factors identified by multivariate analysis for patients undergoing laparoscopic, open colon, and gastric surgery. Am J Infect Control. 2008 Dec; 36(10):727-731.

15. Iqbal M, Khan JA, Rehman S, Saieem SM, Mehboob M, Qayyum A, Aybab GR, Comparative study of potentiality contaminated wound healing in primarily applied stitches and delayed primary closure. J Coll Physicians Surg Pak 1999; 91: 158S-63S

16. Dipiro JT, Martindale RG, Bakst A, Vacani PF, and Watson $P$, Miller MT. Infection in surgical patients: effects on mortality, hospitalization, and post discharge care. Am J Health Syst Pharm 1998; 55:777-81. 